but know of many cases where failure followed, or worsecocaine or coca morphia addiction. And the need of caution against free and frequent use obtains in other cases, for there may come a demand for continued taking that will not be denied.

To summarise. Cocaine may be toxic, sometimes deadly, in large doses. It may give rise to dangerous, or even fatal, symptoms in doses usually deemed safe. The danger, near and remote, is greatest when given under the skin. It may produce a diseased condition, in which the will is prostrate and the patient powerless-a true toxic neurosis, more marked and less hopeful than that from alcohol or opium. Such being my belief, I regard Dr. Hammond's statements mistaken and his conclusions rash and dangerous.

Brooklyn, New York.

\section{MANIPULATION WITHOUT INCISION AS A POSSIBLE TREATMENT IN CERTAIN CASES OF STONE IN THE KIDNEY.}

BY WILLIAM H. BENNETT, F.R.C.S.

IN connexion with the recent discussion on Renal Surgery at the Clinical Society, the following case-which, had time allowed, I intended to have mentioned-presents, I venture to think, some points of interest.

An unmarried woman, thirty years old, of a spare habit and nervous disposition, came under my care as an outpatient at St. George's Hospital in September last, complaining of symptoms which led me to suspect that she was the subject of a calculus in the left kidney. At the same time she presented several indications of "hysteria," and stated that she occasionally suffered from fainting attacks, which were quite unconnected with the symptoms on account of which she applied for treatment. Upon examining the abdomen, which was very thin, deep pressure over the left kidney caused considerable sharp pain and threw the superjacent muscles into rigid contraction. The kidney could be distinctly felt and moved with the hand, and seemed of the natural size and form. Taking into consideration the hysterical tendency of the patient, I was unable to decide, in the absence of any very marked abnormality in the urine, with the exception of a very slight deposit of mucus and pus, whether the case was really one of renal calculus or not. Seeing, however, the ease with which the kidney could be felt, partly by reason of the thinness of the patient, I determined, as drugs afforded no relief, to ensure complete relaxation of the abdominal parietes by the administration of an anæsthetic, and then manipulate the kidney as freely as possible, without previously exposing it by incision, with a view, if the case were one of calculus, to disturbing the stone, and, if it were not too large, perhaps bringing about its passage down the ureter, or, in the event of the symptoms being "hysterical," with the hope of producing a mental effect upon the patient sufficient to relieve her distress. She, however, declined the anæs thetic, and I was compelled to attempt the manipulation without its aid. The patient having been laid on her back upon a couch, the fingers of my left hand were dipped deeply into the abdominal wall over the kidney, the right hand being pressed forwards into the loin. By a little management, the muscles being quite flaccid from the patient having become faint, the kidney could be feit quite easily between the two hands, and was kneaded as thoroughly as the circumstances allowed. The patient, although much discontented with the aching and tenderness which the operation seemed to have caused, was well enough to walk away almost directly afterwards.

Two days later she reappeared at the hospital in a more grateful mood, saying that, having suffered much discomfort for the rest of the day after the manipulation, she was seized as she was going to bed with a most acute pain in the affected loin and side of the abdomen. The pain lasted for about half an hour, during which she vomited twice. All at once an uncontrollable desire to micturate occurred, and the pain immediately ceased. No further pain followed, and there can be little doubt that a small calculus had made its way down the ureter into the bladder, although no evidence of its having passed "per urethram" was forthcoming. Moreover, it is quite possible that the manipula- tion had moved the stone from its resting place in the kidney, and thus brought about its expulsion.

I am aware that an isolated case like the above cannot be taken to necessarily provemuch, since the passage of the calculus may have been a mere coincidence; at the same time I am strongly disposed to attribute the result to the manipulation. This view receives some corroboration from a case which was under the care of one of my colleagues, in which the kidney was exposed and examined without the detection of a stone, although shortly afterwards an attack of renal colic was followed by the expulsion of a very small calculus, which had probably been disturbed during the exploration. Other similar cases have, I believe, occurred. As bearing on the same point, I may here say that it seems most probable that when relief has followed the exposure and manipulation of the kidney without the detection of a stone, the result has been due to an alteration in the position of the calculus produced by the kneading to which the organ has been subjected. That calculi of considerable size may be overlooked both in the lumbar and combined abdominal and lumbar operation for exposing the lidney when the organ is examined by the fingers only is certain, and it is, I believe, from our experience at St. George's Hospital, equally certain that only stones of the smallest size can escape detection when the kidney is thoroughly explored by acupuncture -an operation which has been at present associated with risks which are hardly more than problematic, and at all events less serious than the danger which exists of overlooking calculi of no small size when digital examination is alone employed. Manipulation of the kidney through the parietes without previous incision is possible in certain cases, the number of which is far larger than is generally supposed, when the abdominal walls are not too much loaded with fat, and the muscles have been completaly relaxed by the administration of an anæsthetic. Indeed, I believe the kidney to be, as a rule, far more movable and less fixed in the loin in the living subject than it is usually described to be. In conclusion, I venture to suggest that manipulation without incision is a proceeding worthy of trial as a treatment which may possibly prove of utility in certain cases of renal calculus, not too far advanced, as a means of changing the position of the stone and perhaps effecting its expulsion-a possibility, to my mind, sufficiently strong to commend the process to the attention of physicians as an adjunct to the medical treatment of renal calculus.

Chesterfied-street, Mayfair, W.

\section{WILL THE KNEE JERK DIVIDE TYPHOID FEVER FROM MENINGITIS?}

BY ANGEL MONEY, M.D., M.R.C.P., ASSISTANT PHYSTCLAY TO THE HOSPITAL FOR SICK CHILDREY AND TO THE YICTORIA PARK CHEST HOSPITAL.

DR. HughLINGS $J_{A C K S O N}$ asserted a month ago at the Medical Society of London that loss of the knee jerk might prove of service in the diagnosis of meningitis from typhoid fever, for he had never known the knee jerk to be absent in typhoid fever, whilst he had found it to be wanting in cases which the necropsy ultimately proved to be meningitis. Our "friend in need," the knee jerk, indeed, appears to be considering its apparent triviality of as much, if not more, value than almost any other clinical phenomenon.

At the same meeting of the Medical Society at which Dr. Jackson's announcement was made, Sir Dyce Duckworth seemed to put a damper on the President's suggestion by asserting that the knee jerk might be absent in undoubted typhoid fever. Two years ago I recorded in THE LANCET my experience of the reflex actions and other nervous phenomena in typhoid fever, phthisis, and other continued fevers (pp. 843 and 1069, vol, ii., 1885), and I can only add that further experience does but confirm what I then stated to be the condition of the reflexes and muscles in these various diseases. The suggestion forces itself upon us that prolonged pyrexia with all that it involves, whether in the way of direct deterioration of protoplasm by the fever heat, or of indirect deterioration of the same by collateral consequences of the pyrexia, is the cause of the very general exaggeration of the deep reflexes and muscular irritability to be found in the diseases mentioned. I 
have not seen a case of typhoid fever in which the knee jork was lost; though the jerk may have been absent on the day or so preceding death in fatal cases, which are rare at the age at which tubercular meningitis is common. On the other hand, tubercular meningitis does not always cause the disappearance of the knee jerk. Sometimes the knee jerk is increased in cases of undoubted tubercular meningitis, but only, I believe, when the child is unconscious or nearly so. I have even observed, in company with Dr. Gee, that tapping of the patella tendon on one side caused powerful contraction not only of the quadriceps extensor of the same side, but also of the adductors of the thigh of the opposite side, in a case of tubercular meningitis. Such phenomena will not be found to be very uncommon if they be diligently searched for. I have myself seen them in diphtheritic paralysis, as well as in tubercular meningitis and phthisis. In order to answer so far as is possible the question which forms the title of this brief communication 1 shall formulate the following propositions: Given a case of fever with morbid mental phenomena, without a typical rash, optic neuritis, or choroidal tubercle, or any sign of cranial nerve paralysis or irritation, if the knee jerk is lost on both sides during the illness, and the wasting of muscle is unattended with loss of response to the faradaic current, the diagnosis should be meningitis rather than typhoid fever. If the knee jerk be exaggerated, and if there be ankle clonus, no certain conclusion can be drawn, for these conditions occur both in typhoid fever and in meningitis (and other conditions). But I am inclined to assert-though on this point I desire further observation and investigation - that increase of the jerks (with or without ankle clonus), accompanied by lively spontaneous fickerings (fibrillar contractions) of the muscles, is much more likely to be due to prolonged pyrexia than to direct disturbance of the nervous functions from meningitis or other nervous irritation. If typhoid fever be complicated with myelitis or meningitis-complications of rare occurrence-then the jerk may be lost, but with a fairly large experience ( $I$ have carefully tested the point in twenty-five cases) I have never known it to be absent; whilst in tubercular meningitis its disappearance for a few hours, or a day, or a few days, is by no means rare. A variable state of the knee jerk-e.g., one day present, next day absent, and a third increased-points to meningitis, not fever.

To make what may be considered a curious comparison, I should think that the differential diagnosis of meningitis from mere fevers might be assisted far more by the state of the knee jerk than by the swelling of the spleen; for unless the splenic enlargement be enormous, tubercle as well as typhoid fever and other diserses-e.g., pyæmia - will account for the splenic swelling; whereas absence of the knee jerk, or rather ascertained disappearance of the same, is practically never met with as the simple outcome of prolonged pyrexia. Harley-street, $\mathrm{W}$.

\section{A CASE OF HYDROPHOBIA IN A CHILD.}

Bx R. A. JAMIESON, M.A.,

CONSULTIYG SURGEON TO THE IMPERIAL MARITIME CUSTOMS IN CHINA.

L-_, an English child, male, aged three years and a half, was knocked down by a stray dog on January 4th, 1886, and severely torn about the face by the animal's teeth and claws. The mouth was laid open through the lower lip by a perpendicular cut beginning at the left angle and extending an inch and a half downwards; and through the upper lip by an almost horizontal cut, about one inch in length, reaching from the right nostril towards the left side. The skin and areolar tissue of the right lower eyelid were torn from the muscle, leaving a narrow border of skin perhaps one-sixth of an inch wide below the ciliary margin. The portion thas torn formed nearly a semicircle of one inch radius, the centre corresponding to the middle point of the edge of the lower lid. It was split more or less horizontally by a laceration extending from the internal canthus about half way across the flap, and was rolled into a ball at the inner angle of the orbit, being retained by two slender points of attachment separated by the horizontal laceration, and corresponding to the anterior edge of the lacrymal bone. When unfolded, the flap was bruised and cold, and its external extremity severely crushed.
Under chloroform it was replaced, and the edges sutured and smeared with iodoform ointment. The other wounds were united and covered with collodion. On Jan. 23rd all the wounds had healed, but in consequence of sloughing of the external edge of the flap some slight eversion of the lower lid was threatened. Bleeding had been profuse from all the wounds at the time of the accident. Taking this and the condition and position of the injury to the lower lid into consideration, I did not cauterise the exposed surfaces. It was subsequently remembered that on the 26th and 27th (twenty-third and twenty-fourth days) the child made excuses not to drink milk or tea. He ate, however, porridge and milk, bread and soup, \&c. On the 28 th he ate a quantity of fruit, and seemed to suffer from indigestion. Some castor oil was administered with great difficulty, and he had a warm bath. When he was on the point of being put into the bath he sprang from his mother's arms in apparent fright, and climbed up the back of a high chair " like a monkey." He soon, however, came down, got into the tub himself, and wished to stay in the water. Next morning (29th), when coaxed to take some milk, he would only answer, "by and by" and when at last persuaded to make the attempt he pushed the cup from him. There was no spasm, no mucus in the fauces, and no aerophobia. During the day he repeatedly asked for milk \&c., but refused every thing as soon as it was brought, and was very restless and peevish. A mustard bath was administered at some friend's suggestion, and it did not frighten him. At 7 P.M. he was extremely nervous, and bis legs were trembling. There was no intolerance of light (in fact he seemed pleased to look at the gas), and he paid no attention to the splashing of water close by him. At 10.30 P.M. he was delirious and saw spectres. The slightest touch on the head now produced spasm of respiration. At 11.15 P.M. the following note was made: "Frequen' spasmodic arrest of breathing, immodiately followed by forced inspiration in a series of short gasps. He starts up, momentarily stiff in all his limbs, but there is no clonic convulsions. Fis expression is maniacal, and he agitates his hands battling with spectres. This lasts for about forty-five seconds, when he becomes calm, recognises the people round him, and talks rationally, asking his father, for instance, to 'send the doctor away', and replying, when a drink was offered him, that he did not want it. Between the grand attacks he has minor seizures, due apparently to spasm of the fauces; he retches violently, but brings nothing up." At 11.30 P.M., and again an hour afterwards, injections of one-tenth of a grain of morphia each time were administered, but with hardly perceptible effect, the pupils remaining dilated rather than contracted. On the 30 th, from 1.30 to $5.30 \mathrm{~A}$. M. he spent in spasm of the entire body, so violent as to jerk him out of his mother's arms and fling him two feet from her on to the bed on which she was sitting. At 4 A.M. he began to hawk up viscid mucus, which collected at the corner of his mouth; asking constantly for milk, but refusing it before it could be brought. At 5.30 A.M. one-tenth of a grain of morphia was injected. He did not during this period seem to lose consciousness under the attacks, and in the interval he was perfectly sensible, and his voice was unaltered. He passed urine three times between 1 and 5 A.M. standing up, and was not affected by the sound of falling water. The urine became milky on boiling; it was cleared by a drop of nitric acid. An attempt to relieve thirst by a warm water enema had to be abandoned, as it induced. violent general spasm. Thinking it better to keep the room dark, the gas was lowered, but the change in the light brought on a spasm, and he begged that it should remain bright. At 6 A.M., the last dose of morphia showing no effect beyond causing moderate contraction of the pupils, the saliva becoming more and more abundant, the spasms more violent, frequent, and prolonged, and death seeming imminent, I again gave one-tenth of a grain. All the injections were given in the right buttock. There appeared to be complete insensibility of the skin in this region, as the child made no complaint of the needle prick. Immediately before giving this injection the following note was made: "Each spasm begins with a gulp, followed by the appearance of a little froth at the corners of the mouth. He then momentarily ceases to recognise the people round him, sees some terrifying sight, the lips become livid, he opens his mouth widely in prolonged effort to get air, and a quantity of viscid saliva is suddenly secreted which be hawks up. The end of the attack is marked by his speaking about some indifferent thing in a clear, strong, and natural voice. Conjunctivæ injected faco pale, lips ashy." 